\title{
T-cell transcriptomics from peripheral blood highlights differences between polymyositis and dermatomyositis patients
}

Miranda Houtman ${ }^{1 *}$ D, Louise Ekholm', Espen Hesselberg ${ }^{1}$, Karine Chemin ${ }^{1}$, Vivianne Malmström, Ann M. Reed ${ }^{2}$, Ingrid E. Lundberg ${ }^{1}$ and Leonid Padyukov ${ }^{1}$

\begin{abstract}
Background: Polymyositis (PM) and dermatomyositis (DM) are two distinct subgroups of idiopathic inflammatory myopathies, a chronic inflammatory disorder clinically characterized by muscle weakness and inflammatory cell infiltrates in muscle tissue. In PM, a major component of inflammatory cell infiltrates is CD8+ T cells, whereas in DM, CD4+ T cells, plasmacytoid dendritic cells, and B cells predominate. In this study, with the aim to differentiate involvement of CD4+ and CD8+ T-cell subpopulations in myositis subgroups, we investigated transcriptomic profiles of $T$ cells from peripheral blood of patients with myositis.

Methods: Total RNA was extracted from $C D 4+T$ cells $(P M=8$ and $D M=7)$ and $C D 8+T$ cells $(P M=4$ and $D M=5)$ that were isolated from peripheral blood mononuclear cells via positive selection using microbeads. Sequencing libraries were generated using the Illumina TruSeq Stranded Total RNA Kit and sequenced on an Illumina HiSeq 2500 platform, yielding about 50 million paired-end reads per sample. Differential gene expression analyses were conducted using DESeq2.
\end{abstract}

Results: In CD4+ T cells, only two genes, ANKRD55 and S100B, were expressed significantly higher in patients with PM than in patients with DM (false discovery rate $[F D R]<0.05$, model adjusted for age, sex, HLA-DRB $7^{*} 03$ status, and RNA integrity number [RIN]). On the contrary, in CD8+ T cells, 176 genes were differentially expressed in patients with PM compared with patients with DM. Of these, 44 genes were expressed significantly higher in CD8+ T cells from patients with PM, and 132 genes were expressed significantly higher in CD8+ T cells from patients with DM (FDR $<0.05$, model adjusted for age, sex, and RIN). Gene Ontology analysis showed that genes differentially expressed in CD8+ T cells are involved in lymphocyte migration and regulation of T-cell differentiation.

Conclusions: Our data strongly suggest that CD8+ T cells represent a major divergence between PM and DM patients compared with CD4+ T cells. These alterations in the gene expression in T cells from PM and DM patients might advocate for distinct immune mechanisms in these subphenotypes of myositis.

Keywords: Idiopathic inflammatory myopathies, Polymyositis, Dermatomyositis, T cells, CD4+ T cells, CD8+ T cells, Differential gene expression, RNA sequencing

\footnotetext{
* Correspondence: miranda.houtman@ki.se

'Division of Rheumatology, Department of Medicine, Karolinska Institutet,

Karolinska University Hospital, Stockholm, Sweden

Full list of author information is available at the end of the article
}

(c) The Author(s). 2018 Open Access This article is distributed under the terms of the Creative Commons Attribution 4.0 International License (http://creativecommons.org/licenses/by/4.0/), which permits unrestricted use, distribution, and reproduction in any medium, provided you give appropriate credit to the original author(s) and the source, provide a link to the Creative Commons license, and indicate if changes were made. The Creative Commons Public Domain Dedication waiver (http://creativecommons.org/publicdomain/zero/1.0/) applies to the data made available in this article, unless otherwise stated. 


\section{Background}

Polymyositis (PM) and dermatomyositis (DM) are chronic inflammatory disorders clinically characterized by skeletal muscle weakness and muscle inflammation [1]. Other organs, such as the skin, joints, and lungs, are frequently involved in these disorders. Although the etiology of PM and DM is unknown, certain environmental and genetic factors are important. The major risk factor for these disorders in Caucasian populations is HLA$D R B 1 * 03: 01$ [2-4]. In addition, autoantibodies are found in more than $80 \%$ of the PM and DM patients, supporting a role for the adaptive immune system in the pathogenesis of these disorders [5].

In both PM and DM patients, inflammatory cell infiltrates are commonly found in the affected tissues [6, 7]. In PM, the cellular infiltrates are located mainly in the endomysium surrounding muscle fibers and typically dominated by CD8+ T cells $[8,9]$. In contrast, in patients with $\mathrm{DM}$, the inflammatory cell infiltrates are located mainly in the perimysium and in perivascular areas, and the infiltrates are predominated by CD4 $+\mathrm{T}$ cells with occasional plasmacytoid dendritic cells and B cells [6]. Further phenotyping of T cells in muscle tissue has led to the observation that the muscle-infiltrating T cells in both PM and $\mathrm{DM}$ are predominantly of the $\mathrm{CD} 8+\mathrm{CD} 28^{\text {null }}$ and $\mathrm{CD} 4$ $+\mathrm{CD} 28^{\text {null }}$ phenotypes, which both have cytotoxic properties $[10,11]$. Interestingly, these subpopulations of $\mathrm{T}$ cells can also be detected in peripheral blood of patients with myositis $[10,12]$. Still, the differences in the tissue location of inflammatory cell infiltrates suggest that the underlying immune mechanisms may vary between PM and DM.

In this study, we aimed to investigate whole-genome transcriptomes of CD4+ and CD8+ T cells from peripheral blood in different subsets of patients with idiopathic inflammatory myopathies (IIMs). We used RNA sequencing to identify differentially expressed genes between PM and DM, as well as in patients with both types of IIM, considering $H L A-D R B 1 * 03$ alleles.

\section{Methods}

\section{Patient recruitment}

Initially, 33 consecutive adult individuals with PM or DM (not drug-free) from the Karolinska Hospital Rheumatology Clinic were selected for the study on the basis of diagnosis (PM and DM) and HLA-DRB1*03 status (positive and negative). Patients with myositis visited the clinic between January 21 and April 23, 2014, and were fully validated according to the new European League Against Rheumatism/ American College of Rheumatology classification criteria [13]. Thirty-one of the 33 patients also satisfied the Bohan and Peter criteria $[14,15]$. Extensive clinical data, including disease phenotypes and treatment regimen, were collected from clinical records by experienced rheumatologists. All patients gave written consent for their participation in the study. The study was approved by the Stockholm regional ethics board.

\section{Autoantibody detection}

Patient sera were analyzed by RNA and protein immunoprecipitation for the presence of autoantibodies against Jo1, PL12, PL7, OJ, EJ, KS, Mi-2, MDA5, TIF-1 $\gamma$, SRP, PM-Scl, Ro52, Ro60, U1RNP, and Ku. Sera collected after 2013 were screened using a validated line immunoassay system (EUROLINE myositis panel 4; EUROIMMUN AG, Lübeck, Germany) according to the manufacturer's instructions or by enzyme-linked immunosorbent assays for the presence of myositis-specific autoantibodies or myositis-associated autoantibodies.

\section{HLA typing}

$H L A$ typing was performed by sequence-specific primer PCR (HLA-DR low-resolution kit; Olerup SSP, Stockholm, Sweden) and analyzed by agarose gel electrophoresis [16]. An interpretation table was used to determine the specific genotype according to the manufacturer's instructions.

\section{Blood sampling and cell sorting}

Patients' blood was collected in heparin tubes $(40-50 \mathrm{ml}$ in total), and peripheral blood mononuclear cells (PBMCs) were isolated by density gradient centrifugation using Ficoll density gradient medium (GE Healthcare Bio-Sciences AB, Uppsala, Sweden). CD4+ cells and CD8+ cells were isolated from the PBMCs via positive selection using CD4 or CD8 MicroBeads on an autoMACS ${ }^{\odot}$ Pro Separator (Miltenyi Biotec Norden AB, Lund, Sweden). Flow cytometry was used to determine the purity of some of the sorted T-cell samples, and over $90 \%$ of CD45+ cells expressed CD4 $(n=5)$ or CD8 $(n=5)$. The following antibodies were used: CD45 (HI30; BioLegend, San Diego, CA, USA), CD4 (OKT4; BioLegend), and CD8 (SK1; BD Biosciences, Stockholm, Sweden).

\section{RNA sequencing}

Total RNA was extracted with the RNeasy Mini Kit (Qiagen AB, Sollentuna, Sweden) according to the manufacturer's instructions. Samples were treated with DNase (Qiagen) for 20 minutes at room temperature to avoid contamination with genomic DNA. The quality of each RNA sample was characterized using a RNA 6000 Nano Chip (Agilent Technologies Sweden AB, Kista, Sweden) on the Agilent Bioanalyzer 2100. Fifteen CD4+ T-cell samples and nine CD8+ T-cell samples met the RNA quality criteria (RNA integrity number [RIN] > 4) and were sequenced. The RNA was fragmented and prepared into sequencing libraries using the TruSeq Stranded Total RNA Sample Preparation Kit (Illumina, San Diego, CA, USA) with ribosomal depletion using Ribo-Zero $(2 \times 125 \mathrm{bp}$; Illumina) and analyzed on an 
Illumina HiSeq 2500 sequencer (SNP\&SEQ Technology Platform, Uppsala, Sweden). On average, 50 million reads were produced per sample. Raw read quality was evaluated using FastQC. Prefiltering on quality of reads using cutadapt (version 1.9.1) was applied (-q 30 -a AGATCGG AAGAGCACACGTCTGAACTCCAGTCAC -A AGATC GGAAGAGCGTCGTGTAGGGAAAGAGTGTAGATCT CGGTGGTCGCCGTATCATT -m 40). Filtered reads were aligned to the hg38 assembly and quantified using STAR (version 2.5.1b) [17] with default settings.

\section{Cell-type enrichment analysis}

The xCell tool [18] was used to identify cellular heterogeneity in the CD4+ and CD8+ T-cell subsets from gene expression data. $x$ Cell uses the expression levels ranking (transcripts per million), and these were obtained using Salmon (version 0.8.2) [19].

\section{Differential gene expression analysis}

Raw expression counts were adjusted for library size using the R package DESeq2 (version 1.16.1) [20]. Prefiltering of low-count genes was performed to keep only genes that have at least 50 reads in total. Principal component analysis (PCA) was used to identify outliers. For each sample, the first five principal components (PCs) were extracted and correlated with available clinical and technical data. For the CD4+ T-cell subset, age group $(<$ 60 and $\geq 60$ years), sex, HLA-DRB1*03 status (positive and negative), and RIN value were used as covariates in the analyses. The formula used for defining the model was the following:

$$
\begin{aligned}
\text { Geneexpression } & \text { agegroup }+ \text { sex } \\
& +H L A-D R B 1 * 03 \text { status } \\
& + \text { RINvalue }+ \text { diagnosis }
\end{aligned}
$$

For the CD8+ T-cell subset, sex, age group $(<60$ and $\geq 60$ years), and RIN value were used as covariates in the analyses. The formula used for defining the model was the following:

$$
\begin{gathered}
\text { Geneexpression } \sim \text { agegroup }+ \text { sex }+ \text { RINvalue } \\
+ \text { diagnosis }
\end{gathered}
$$

Owing to possible contamination of samples with other cell types, differential gene expression analyses were performed in two stages. The analyses were performed first on all samples and second on a subset of samples excluding potential outliers. The differentially expressed genes that overlapped between the two ana-

\begin{tabular}{|c|c|c|c|c|c|c|c|c|c|}
\hline Patient & CD4 & CD8 & Age (years) & Sex & Diagnosis & Autoantibodies & HLA-DRB1*03 status (genotype) & Prednisone & Other treatment \\
\hline CEL-004 & $\times$ & & 76 & Female & PM, prob & PM-Scl & Positive $\left({ }^{*} 03 /{ }^{*} 07\right)$ & Yes & MTX \\
\hline CEL-005 & $\times$ & & 48 & Male & DM, def & SSA & Negative $\left({ }^{*} 11 /{ }^{*} 11\right)$ & Yes & AZA, TAC \\
\hline CEL-006 & $\times$ & & 60 & Male & PM, pos & SRP & Positive $\left({ }^{*} 03 /{ }^{*} 15\right)$ & Yes & - \\
\hline CEL-008 & $\times$ & $\times$ & 47 & Male & DM, prob & MDA5 & Negative $(* 11 / * 16)$ & Yes & AZA, ABT \\
\hline CEL-009 & & $x$ & 80 & Male & PM, def & Jo1 & Positive $\left({ }^{*} 03 /{ }^{*} 13\right)$ & Yes & - \\
\hline CEL-010 & $\times$ & & 74 & Female & PM, prob & None & Positive $\left({ }^{*} 03 /{ }^{*} 10\right)$ & No & IVlg \\
\hline CEL-011 & $\times$ & $x$ & 55 & Female & DM, def & $\mathrm{Mi}-2$ & Negative $\left({ }^{*} 07 /{ }^{*} 16\right)$ & Yes & MTX \\
\hline CEL-014 & & $x$ & 74 & Male & DM, def & SSA & Negative $\left({ }^{*} 07 /{ }^{*} 11\right)$ & No & - \\
\hline CEL-016 & $x$ & & 78 & Male & DM, def & None & Positive $\left({ }^{*} 03 /{ }^{*} 11\right)$ & Yes & MMF \\
\hline CEL-017 & $x$ & $x$ & 80 & Female & PM, def & None & Positive $\left({ }^{*} 03 /{ }^{*} 13\right)$ & Yes & MTX \\
\hline CEL-019 & $\times$ & & 46 & Female & DM, def & PM-SCl & Positive $\left({ }^{*} 03 /{ }^{*} 04\right)$ & No & MTX \\
\hline CEL-020 & $\times$ & & 61 & Female & PM, def & PM-SCl & Positive $\left({ }^{*} 01 /{ }^{*} 03\right)$ & Yes & MMF \\
\hline CEL-023 & $x$ & & 58 & Male & DM, def & TIF1Y & Negative $\left({ }^{*} 04 /{ }^{*} 07\right)$ & Yes & AZA, RIX \\
\hline CEL-024 & $\times$ & $x$ & 63 & Female & PM, def & SSA & Positive $\left({ }^{*} 03 /{ }^{*} 08\right)$ & Yes & $A Z A, C s A$ \\
\hline CEL-027 & & $x$ & 65 & Male & PM, def & Jo1 & Positive $\left(* 03 /{ }^{*} 08\right)$ & Yes & - \\
\hline CEL-030 & $\times$ & & 40 & Female & PM, def & Jo1 & Positive $\left({ }^{*} 03 /{ }^{*} 03\right)$ & Yes & - \\
\hline CEL-031 & $\times$ & $\times$ & 68 & Female & DM, def & TIF1Y & Negative $\left({ }^{*} 01 /{ }^{*} 11\right)$ & Yes & - \\
\hline CEL-033 & & $\times$ & 42 & Male & DM, def & MDA5 & Negative $\left({ }^{*} 04 /{ }^{*} 07\right)$ & Yes & MTX \\
\hline CEL-034 & $x$ & & 56 & Female & PM, def & Jo1, SSA, SSB & Negative $\left({ }^{*} 11 /{ }^{*} 16\right)$ & Yes & MTX \\
\hline
\end{tabular}
lyses were taken as robust evidence for significant findings in order to exclude false-positive findings due to heterogeneity in the CD4+ and CD8+ T-cell subsets.

Table 1 Clinical characteristics of patients with myositis at time of blood sampling

Abbreviations: ABT Abatacept, AZA Azathioprine, CSA Cyclosporine A, Def Definite, DM Dermatomyositis, IVIg Intravenous immunoglobulin, MMF Mycophenolate mofetil, MTX Methotrexate, PM Polymyositis, Pos Possible, Prob Probable, RIX Rituximab, SRP Signal recognition particle, TAC Tacrolimus

Demographic and clinical characteristics of patients with myositis in the CD4+ $(n=15)$ and CD8+ T-cell subsets $(n=9)$ at time of blood sampling. The patients were classified according to the new European League Against Rheumatism/American College of Rheumatology classification criteria [13] 
The default DESeq2 options were used, including log fold change shrinkage. We considered differentially expressed genes when the Benjamini-Hochberg adjusted $p$ value (false discovery rate $[\mathrm{FDR}])$ was $<0.05$.

\section{Functional enrichment analysis}

To further understand the biological relevance and associated pathways of the differentially expressed genes, functional enrichment analysis was performed using the Gene Ontology (GO) database (released on 2 February 2018). Fisher's exact test with FDR correction $(<0.05)$ was used to determine significantly enriched GO biological processes.

\section{Results}

\section{Differential gene expression in CD4+ T cells of PM and DM patients}

The clinical characteristics of patients with myositis in the CD4+ T-cell subset are summarized in Table 1. No significant differences were found in patients with PM compared with patients with DM regarding disease activity measures and laboratory data (Additional file 1 : Table S1 and S2).

Because PM and DM represent two similar but clinically distinct diseases, we searched for differentially expressed genes in CD4+ $\mathrm{T}$ cells in PM versus $\mathrm{DM}$ patients. First, the whole-genome expression pattern in CD4+ T cells of PM and DM patients was examined by PCA. The first two PCs did not significantly separate between PM and DM (Fig. 1a), suggesting that, in general, the overall gene expression in CD4 $+\mathrm{T}$ cells from patients with $\mathrm{PM}$ or $\mathrm{DM}$ is similar. At the first analytical stage, we performed differential gene expression analysis using DESeq2 with sex, age group, HLA-DRB1*03 status, and RIN value as covariates. Based on the cutoff criteria of Benjamini-Hochberg based FDR correction of $<0.05$, 13 genes were found to be differentially expressed. Among these genes, six were expressed higher in PM patients and seven were expressed higher in DM patients (Fig. 1b and Additional file 2: Table S6).

The PCA plot shown in Fig. 1a indicates three potential outliers with a PC1 score lower than -20 . These three samples represent higher gene expression levels related to monocytes according to the xCell tool (Additional file 3: Figure S1). To exclude the possibility that the differentially expressed genes were obtained because of a difference in cell composition, at the second analytical stage, we removed the three potential outliers from the analysis. This did not affect clustering of PM and DM samples in PCA (Fig. 2a). Using the same covariates as above, four genes were found to be differentially expressed in CD4+ T cells comparing PM patients with
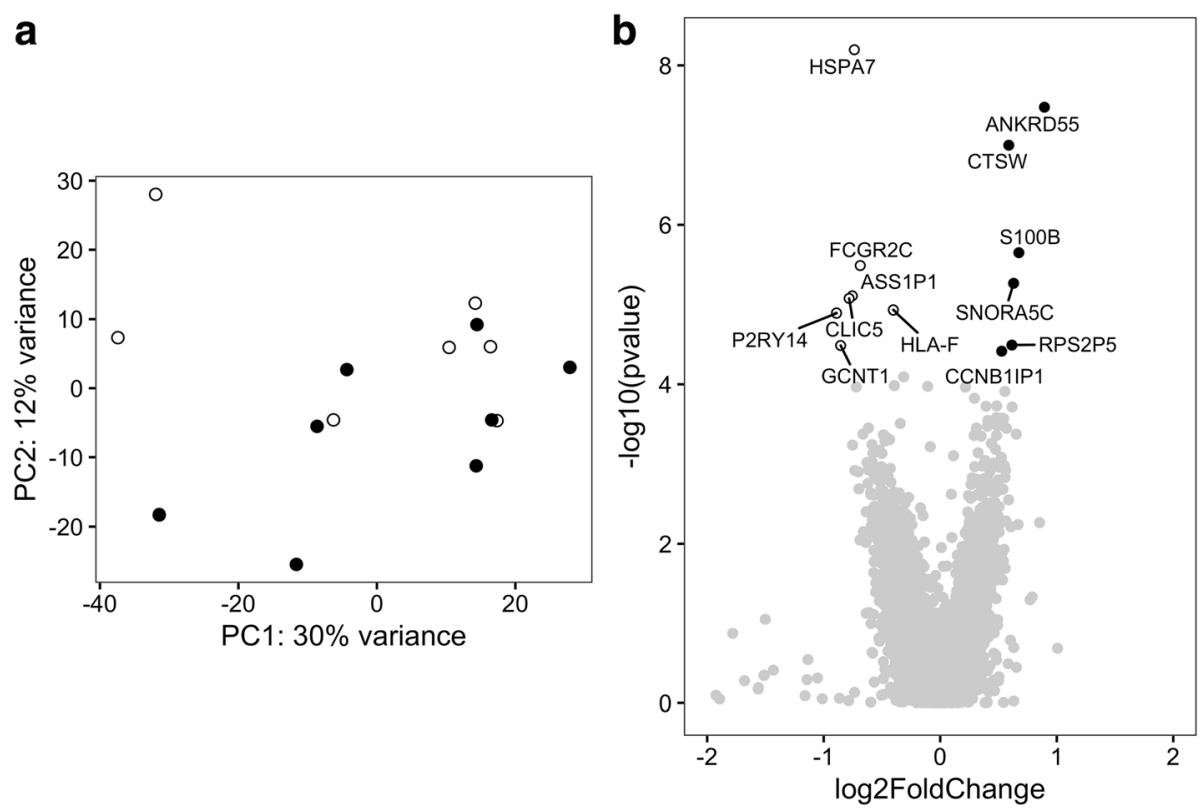

Fig. 1 Gene expression profile in CD4+ T cells of polymyositis (PM) and dermatomyositis (DM) patients. a Principal components (PCs) 1 and 2 plotted according to the diagnosis of the patients in a dataset of 21,008 genes $(n=15)$. Samples from patients with PM are represented by filled circles, and those from DM patients are represented by open circles. b Differential genome-wide transcriptomic profile for the contrast between PM and DM in CD4+ T cells. The fold changes $\left(\log _{2}\right)$ are shown on the $x$-axis, and the $p$ values $\left(-\log _{10}\right)$ are shown on the $y$-axis. The genes that are expressed significantly higher in PM are shown as filled circles, and the genes expressed significantly higher in DM are shown as open circles. A false discovery rate threshold of $5 \%$ based on the method of Benjamini-Hochberg was used to identify significant differentially expressed genes 


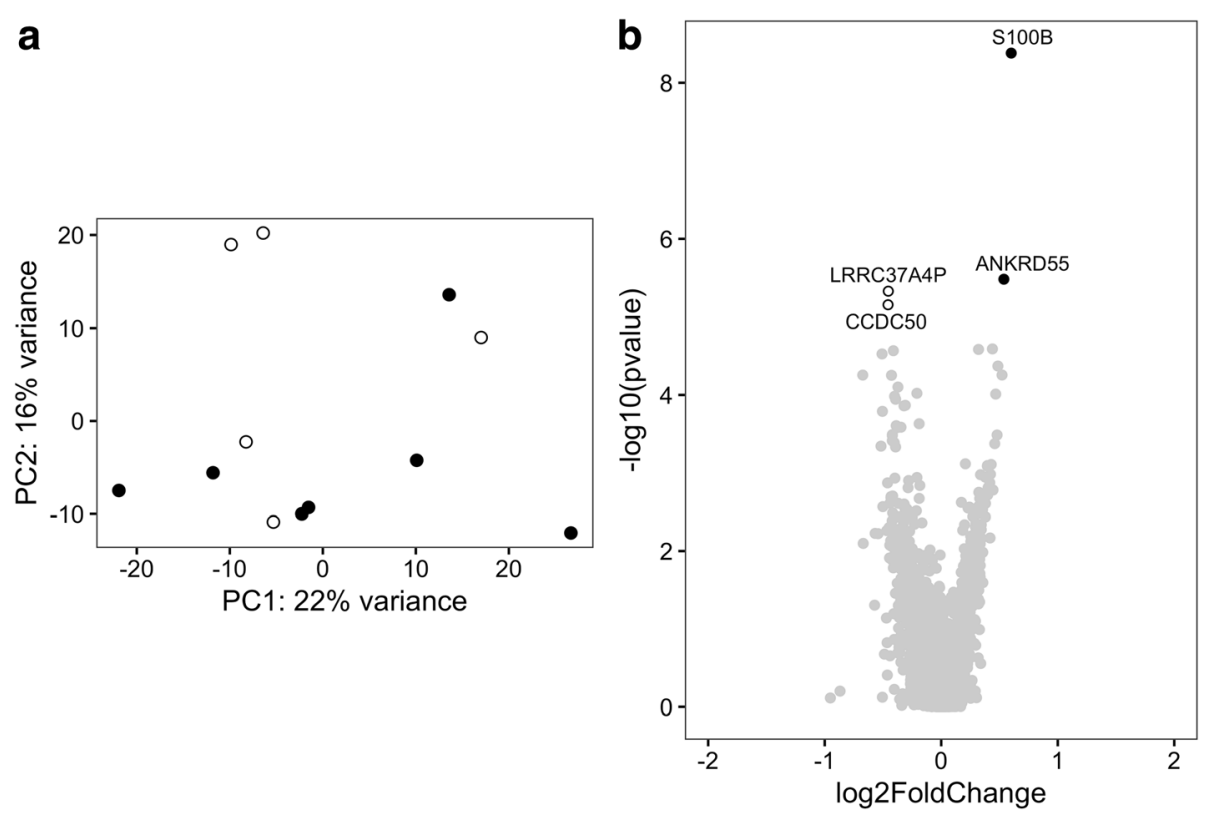

Fig. 2 Gene expression profile in CD4+ T cells of polymyositis (PM) and dermatomyositis (DM) patients excluding potential outliers. a Principal components (PCs) 1 and 2 plotted according to the diagnosis of the patients in a dataset of 20,091 genes $(n=12)$. Samples from patients with PM are represented by filled circles, and those from patients with DM are represented by open circles. $\mathbf{b}$ Differential genome-wide transcriptomic profile for the contrast between PM and DM in CD4+ T cells. The fold changes $\left(\log _{2}\right)$ are shown on the $x$-axis, and the $p$ values $\left(-\log _{10}\right)$ are shown on the $y$-axis. The genes that are expressed significantly higher in PM are shown by filled circles, and the genes expressed significantly higher in DM are shown by open circles. A false discovery rate threshold of $5 \%$ based on the method of Benjamini-Hochberg was used to identify significant differentially expressed genes
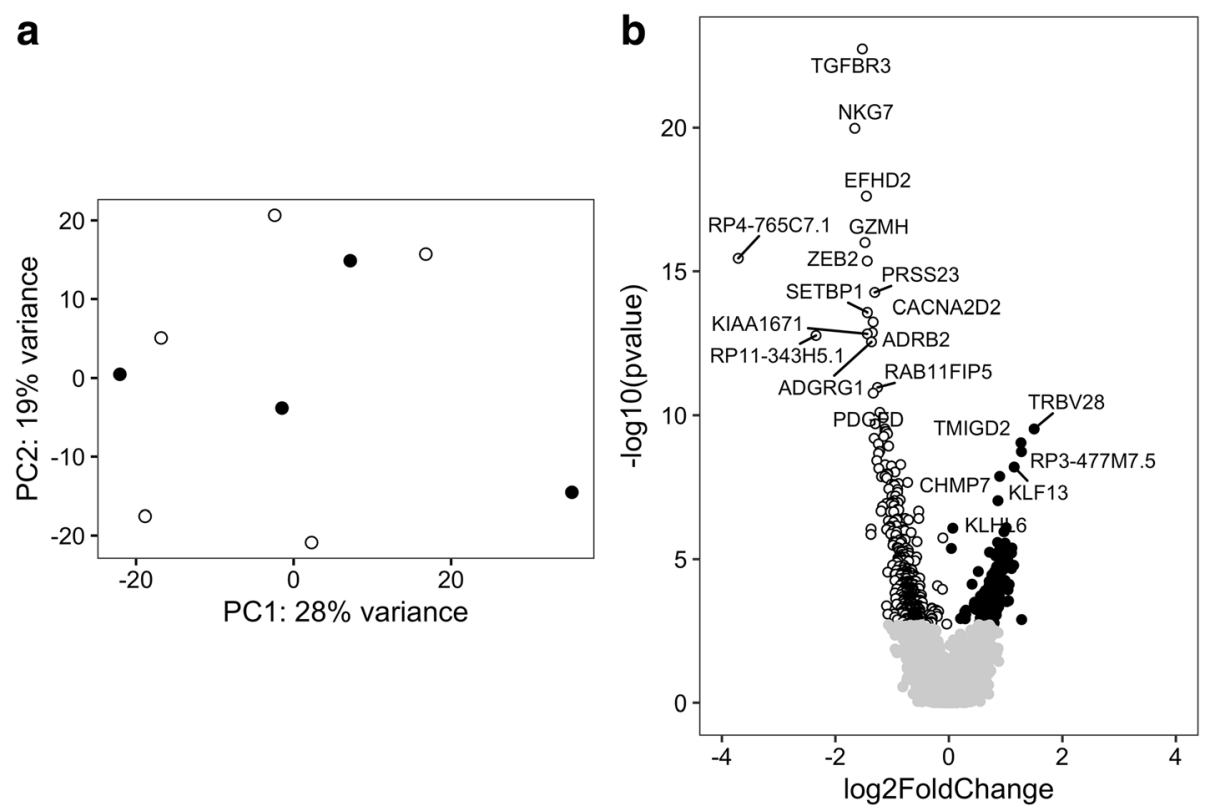

Fig. 3 Gene expression profile in CD8+ T cells of polymyositis (PM) and dermatomyositis (DM) patients. a Principal components (PCs) 1 and 2 plotted according to the diagnosis of the patients in a dataset of 18,696 genes $(n=9)$. Samples from patients with PM are represented by filled circles, and those from patients with DM are represented by open circles. $\mathbf{b}$ Differential genome-wide transcriptomic profile for the contrast between PM and DM in CD8+ T cells. The fold changes $\left(\log _{2}\right)$ are shown on the $x$-axis, and the $p$ values $\left(-\log _{10}\right)$ are shown on the $y$-axis. The genes that are expressed significantly higher in PM are shown by filled circles, and the genes expressed significantly higher in DM are shown by open circles. A false discovery rate threshold of $5 \%$ based on the method of Benjamini-Hochberg was used to identify significant differentially expressed genes. The symbols of the differentially expressed genes with an adjusted $p$ value $<5 \times 10^{5}$ and $<5 \times 10^{8}$ are shown for PM and DM, respectively 
DM patients by applying an FDR correction cutoff of < 0.05 . Two genes had a higher expression in CD4+ T cells of patients with PM compared with patients with DM, and two genes had a higher expression in CD4+ T cells of patients with DM compared with patients with PM (Fig. 2b and Additional file 2: Table S7). Thus, after accounting for possible contamination of the CD4+ T-cell population with monocytes, we considered only the genes that were found to be differentially expressed at both analytical stages. These analyses indicate that in CD4+ T cells, ANKRD55 and S100B had a higher expression in CD4+ T cells of patients with PM compared with patients with DM.

\section{Differential gene expression in CD8+ T cells of PM and DM patients}

The clinical characteristics of patients with myositis in the CD8+ T-cell subset are summarized in Table 1. No significant differences were found in patients with PM compared with patients with DM regarding disease activity measures and laboratory data (Additional file 1: Table S1 and S3).

Another cell type that is commonly found in affected tissues of patients with myositis are CD8+ $\mathrm{T}$ cells.
Therefore, we also searched for differentially expressed genes between PM and DM in CD8+ T cells. First, the gene expression pattern in $\mathrm{PM}$ and $\mathrm{DM}$ was examined by PCA. PCA showed no clustering of PM and DM (Fig. 3a), which suggests that the overall gene expression in PM and DM is similar in CD8+ T cells. To identify genes that are differentially expressed between PM and DM, DESeq2 was used with sex, age group, and RIN value as covariates at the first analytical stage. Upon applying Benjamini-Hochberg-based FDR correction of < 0.05 , we found that 588 genes were differentially expressed between PM and DM. Among these genes, 182 had a higher expression in CD8+ T cells of patients with PM patients compared with DM patients, and 406 had a higher expression in CD8+ T cells of patients with DM compared with patients with PM (Fig. 3b and Additional file 4: Table S8).

The PCA plot shown in Fig. 3a indicates one potential outlier with a PC1 score $>20$. This sample clustered together with the CD4+ T-cell samples (data not shown) and was removed from the analysis at the second analytical stage. After removing this sample from the analysis, the PCA showed that the overall gene expression remained similar in PM and DM (Fig. 4a). Based on the cutoff criteria of FDR $<0.05,308$ genes were found to be
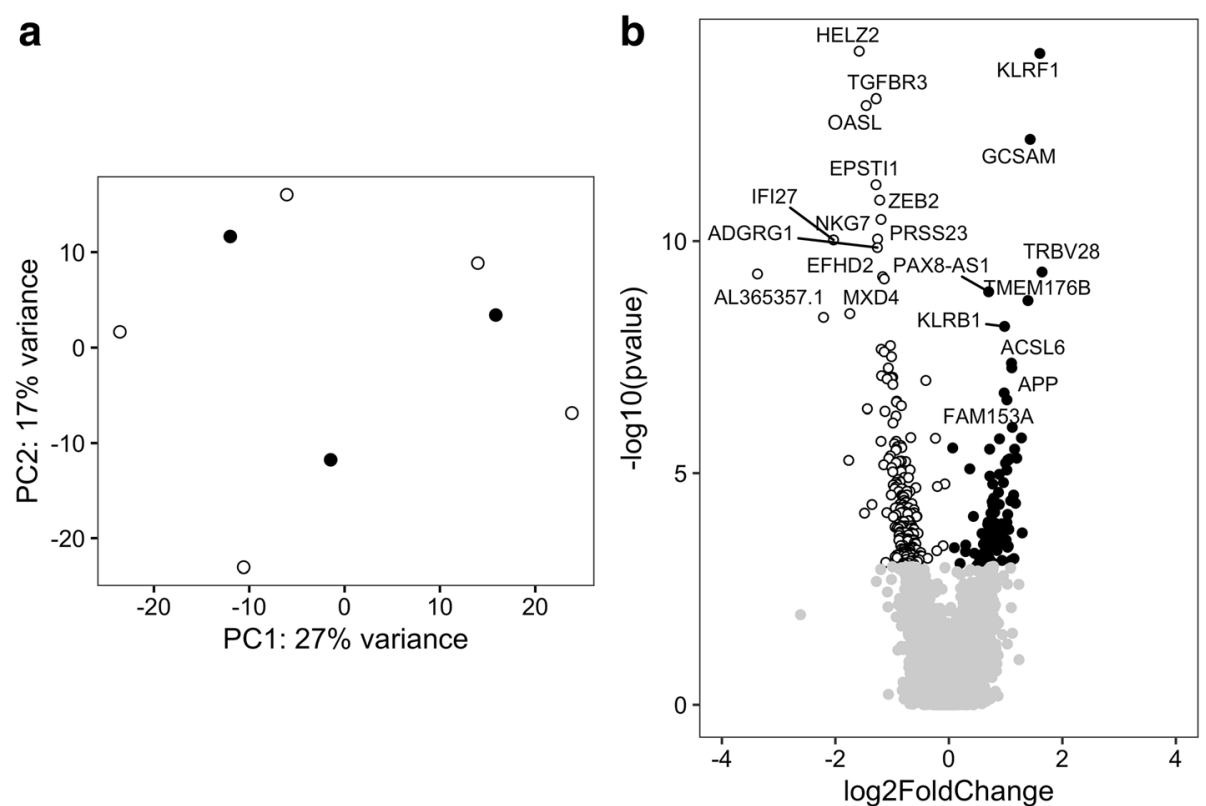

Fig. 4 Gene expression profile in CD8+ T cells of polymyositis (PM) and dermatomyositis (DM) patients excluding potential outliers. a Principal components (PCS) 1 and 2 plotted according to the diagnosis of the patients in a dataset of 18,289 genes $(n=8)$. Samples from patients with PM are represented by filled circles, and those from patients with DM are represented by open circles. $\mathbf{b}$ Differential genome-wide transcriptomic profile for the contrast between PM and DM in CD8+ T cells. The fold changes $\left(\log _{2}\right)$ are shown on the $x$-axis, and the $p$ values $\left(-\log _{10}\right)$ are shown on the $y$-axis. The genes that are expressed significantly higher in PM are shown by filled circles, and the genes expressed significantly higher in DM are shown by open circles. A false discovery rate threshold of $5 \%$ based on the method of Benjamini-Hochberg was used to identify significant differentially expressed genes. The symbols of the differentially expressed genes with an adjusted $p$ value $<1 \times 10^{4}$ and $<1 \times 10^{6}$ are shown for PM and DM, respectively 
differentially expressed in CD8+ T cells comparing PM patients with DM patients. Among these genes, 107 genes had a higher expression in CD8+ T cells of PM patients compared with patients with DM, and 201 genes had a higher expression in CD8 + T cells of DM patients compared with PM patients (Fig. 4b and Additional file 4: Table S9).

Thus, after accounting for heterogeneity in the CD8+ T-cell subset, we considered only the genes that were found to be differentially expressed at both analytical stages. Together, a total of 44 genes were commonly expressed higher in CD8+ T cells of patients with PM compared with patients with DM (Table 2), and 132 genes were commonly expressed higher in CD8+ T cells of patients with DM compared with patients with PM (Table 3).

To identify enriched biological processes and pathways for the 176 genes that were differentially expressed between PM and DM, the GO database was used. Using Fisher's exact test with FDR correction $(<0.05)$, the enriched GO biological processes included lymphocyte migration and regulation of T-cell differentiation (Table 4 and Additional file 5: Table S10).

\section{Differential gene expression in CD4+ T cells of HLA- $D R B 1 * 03$-positive and -negative myositis patients} HLA-DRB1*03 haplotype is the major genetic risk factor for myositis. Therefore, we searched for differentially expressed genes between HLA-DRB1*03-positive and -negative myositis patients in CD4+ T cells. No significant differences were found in patients with $H L A$ $D R B 1 * 03$-positive and -negative myositis regarding disease activity measures and laboratory data (Table 1 and Additional file 1: Tables S4 and S5). The gene expression pattern in $H L A-D R B 1 \% 03$-positive and -negative myositis was examined by PCA, but the first PCs did not separate $H L A-D R B 1$ \%03-positive from $H L A-D R B 1$ *03-negative myositis patients (Fig. 5a), suggesting that these patients are similar on a high genomic level. At the first analytical stage, we performed differential expression analysis using DESeq2 with sex, age group, diagnosis, and RIN value as covariates. This resulted in eight genes that were differentially expressed between HLA-DRB1*03-positive and -negative myositis (FDR < 0.05). Of these genes, one had a higher expression in $H L A-D R B 1 * 03$-positive patients with myositis, and seven had a higher expression in HLA-DRB1*03-negative patients with myositis (Fig. $5 \mathrm{~b}$ and Additional file 6: Table S11).

Excluding the potential outliers, which represent higher gene expression levels linked to monocytes, did not affect the PCA (Fig. 6a). At the second analytical stage, we found that although $H L A-D R B 1 * 03$-positive and -negative myositis are not separated by the first
PCs, 12 genes were differentially expressed in CD4+ T cells in comparison of myositis patients with different genotypes. Among these, five genes had a higher expression in CD4+ T cells from HLA-DRB1*03-positive patients with myositis, and eight genes had a higher expression in CD4+ T cells from HLA-DRB1*03-negative patients with myositis (Fig. $6 \mathrm{~b}$ and Additional file 6: Table S12). Finally, we considered only the genes that were found to be differentially expressed at both analytical stages. PI4KAP1 was found to have a higher expression in CD4+ T cells of HLA-DRB1*03-positive patients with myositis, and TRGC2, CTSW, HPCAL4, ZNF683, and $G O L G A 8 B$ were found to have a higher expression in CD4+ T cells of $H L A-D R B 1 * 03$-negative patients with myositis.

\section{Discussion}

In our study, we observed significantly more differentially expressed genes in the CD8+ T-cell subset than in the CD4+ T-cell subset when comparing PM and DM patients. In CD8+ T cells, we identified 176 genes that were differentially expressed between PM and DM. In contrast, in CD4+ T cells, only two genes, ANKRD55 and $S 100 B$, were found to be differentially expressed between PM and DM. To our knowledge, this is the first study comparing transcriptomic profiles of CD4+ and CD8+ T cells between DM and PM patients. Our data align with the understanding that PM and DM have many common features but differ in genetic architecture and immunohistopathological characteristics. Our findings, together with previous observations, suggest that immune mechanisms related to subpopulations of $\mathrm{T}$ cells may significantly vary between these subphenotypes of myositis and also emphasize CD8+ T cells as being of interest both in patients with PM and in those with DM [10, 21, 22].

PM and DM have been modeled as subgroups of myositis in which muscle tissues are infiltrated by $\mathrm{T}$ cells, mainly CD8+ T cells in PM and CD4+ T cells in DM [6-9]. More recently, we have demonstrated an overlapping phenotype among the muscle-infiltrating $\mathrm{T}$ cells, regardless of their CD4 or CD8 lineage, in that they both display a cytotoxic signature in combination with the absence of the costimulatory CD28 receptor $[10,11]$. Such differentiated $\mathrm{T}$ cells can also be detected in peripheral blood of patients with PM and DM, reflecting the systemic course of autoimmune disorders [10, 12].

In CD8+ T cells of PM and DM patients, 176 genes were differentially expressed. Interestingly, we noted relatively high expression of GZMH and GZMB in CD8 $+\mathrm{T}$ cells of DM patients compared with CD8+ T cells of PM patients. The protein encoded by GZMB is granzyme $\mathrm{B}$ and its secretion by $\mathrm{CD} 28^{\text {null }} \mathrm{T}$ cells may cause 
Table 2 Genes expressed significantly higher in CD8+ T cells of patients with polymyositis than in those with dermatomyositis

\begin{tabular}{ll}
\hline Gene symbol & Gene name \\
\hline TRBV28 & T cell receptor beta variable 28
\end{tabular}

RP3-477M7.5

TMIGD2

KLF13

CA6

TMTC1

LINC00402

TRBV30

IL6R

EPHA1

XKR9

GABPB1-ASI

LAPTM $4 B$

EPHAT-AS1

CAMSAP2

AC012636.1

RP11-28F1.2

CHMP7

SYNJ2

KLHL6

PRKCQ-ASI

CASP10

TXK

CD27

TBC1D4

CLN5

JAML

FAM153A

TNFRSF10D

DHX32

STRBP

AL034550.2

DGKA

COX10-AS1

GCSAM

SLC7A6

ACSL6
Transmembrane and immunoglobulin domain containing 2

Kruppel like factor 13

Carbonic anhydrase 6

Transmembrane and tetratricopeptide repeat containing 1

Long intergenic non-protein coding RNA 402

$\mathrm{T}$ cell receptor beta variable 30 (gene/pseudogene)

Interleukin 6 receptor

$\mathrm{EPH}$ receptor $\mathrm{A} 1$

XK related 9

GABPB1 antisense RNA 1

Lysosomal protein transmembrane 4 beta

EPHA1 antisense RNA 1 associated protein family member 2

Uncharacterized LOC101929215

Charged multivesicular body protein 7

Synaptojanin 2

Kelch like family member 6

PRKCQ antisense RNA 1

Caspase 10

TXK tyrosine kinase

CD27 molecule

TBC1 domain family member 4

CLN5, intracellular trafficking protein

Junction adhesion molecule like

Family with sequence similarity 153 member A

TNF receptor superfamily member $10 d$

DEAH-box helicase 32 (putative)

Spermatid perinuclear RNA binding protein

Uncharacterized LOC101929698

Diacylglycerol kinase alpha

COX10 antisense RNA 1

Germinal center associated signaling and motility

Solute carrier family 7 member 6

Acyl-CoA synthetase long chain family
Calmodulin regulated spectrin
Table 2 Genes expressed significantly higher in CD8+ T cells of patients with polymyositis than in those with dermatomyositis (Continued)

\begin{tabular}{ll}
\hline Gene symbol & Gene name \\
\hline AKAP7 & member 6 \\
AP005131.6 & A-kinase anchoring protein 7 \\
UXS1 & UDP-glucuronate decarboxylase 1 \\
PAX8-AS1 & PAX8 antisense RNA 1 \\
C210rf33 & Chromosome 21 open reading \\
& frame 33
\end{tabular}

RP11-65/12.1

GSTM1

Glutathione S-transferase mu 1

The table demonstrates the genes that overlap between the two analytical stages and have a significantly higher expression in CD8+ T cells of patients with polymyositis than in those with dermatomyositis. A false discovery rate threshold of $5 \%$ based on the method of Benjamini-Hochberg was used to identify significant differentially expressed genes

muscle cell damage [11]. Furthermore, granzyme B cleavage sites have been identified in autoantigens, such as FHL1 and HisRS, targeted in autoimmune disorders, including myositis [23, 24]. Moreover, two T-cell receptor (TCR) beta variable genes, TRBV28 and TRBV30, had a higher expression in CD8+ T cells of patients with PM than in patients with DM. TRBV28 has been found to be one of the most common TCR variable segments in muscle tissue of myositis patients carrying the $H L A-D R B 1 * 03$ allele [25]. This aligns well with the fact that in our analysis of the CD8+ T-cell subset, all PM patients are $H L A-D R B 1 * 03$-positive and all DM patients are HLA-DRB1*03-negative (Table 1). The TCR beta variable genes are probably differentially expressed due to the HLA status of these patients and might reflect the expansion of pathogenic T-cell clones in this subset of patients. In addition, TGFB1, ZEB2, and SMAD7 had a higher expression in CD8+ T cells of patients with DM than in those with PM. This may suggest that transforming growth factor- $\beta$ signaling [26-29] is upregulated in CD8+ T cells of DM patients compared with PM patients.

In CD4+ T cells, two genes, ANKRD55 and S100B, had a higher expression in PM than in DM. ANKRD55 encodes ankyrin repeat domain-containing protein 55 , which mediates protein-protein interactions [30]. Interestingly, single-nucleotide polymorphisms in this gene have previously been associated with several autoimmune disorders, including rheumatoid arthritis [31-33], Crohn's disease [34], and multiple sclerosis [35]. A study to reveal the function of this gene in the context of immune function is pending. $S 100 B$ encodes a member of the S100 protein family and is involved in the calcium-dependent regulation of a variety of intracellular activities [36]. S100B is 
Table 3 Genes expressed significantly higher in CD8+ T cells of patients with dermatomyositis than in those with polymyositis

\begin{tabular}{|c|c|}
\hline Gene symbol & Gene name \\
\hline AL365357.1 & Ribosomal protein S14 pseudogene 2 \\
\hline AL591846.1 & Ribosomal protein S14 pseudogene 1 \\
\hline NKG7 & Natural killer cell granule protein 7 \\
\hline TGFBR3 & $\begin{array}{l}\text { Transforming growth factor beta } \\
\text { receptor } 3\end{array}$ \\
\hline GZMH & Granzyme H \\
\hline EFHD2 & EF-hand domain family member D2 \\
\hline ZEB2 & Zinc finger E-box binding homeobox 2 \\
\hline KIAA1671 & KIAA1671 \\
\hline SETBP1 & SET binding protein 1 \\
\hline FAM118A & $\begin{array}{l}\text { Family with sequence similarity } 118 \\
\text { member A }\end{array}$ \\
\hline$A D G R G 1$ & Adhesion G protein-coupled receptor G1 \\
\hline ADRB2 & Adrenoceptor beta 2 \\
\hline CACNA2D2 & $\begin{array}{l}\text { Calcium voltage-gated channel auxiliary } \\
\text { subunit alpha2delta } 2\end{array}$ \\
\hline PDGFD & Platelet-derived growth factor D \\
\hline SH3TC1 & $\begin{array}{l}\text { SH3 domain and tetratricopeptide } \\
\text { repeats } 1\end{array}$ \\
\hline PRSS23 & Serine protease 23 \\
\hline TBKBP1 & TBK1 binding protein 1 \\
\hline \multicolumn{2}{|l|}{ AC009951.1 } \\
\hline RAB11FIP5 & RAB11 family interacting protein 5 \\
\hline GNAO1 & G protein subunit alpha 01 \\
\hline MUC16 & Mucin 16 , cell surface associated \\
\hline \multicolumn{2}{|l|}{ RP11-107E5.2 } \\
\hline KIF19 & Kinesin family member 19 \\
\hline CST7 & Cystatin F \\
\hline SMAD7 & SMAD family member 7 \\
\hline LINC02086 & $\begin{array}{l}\text { Long intergenic non-protein coding } \\
\text { RNA } 2086\end{array}$ \\
\hline AC040970.1 & Uncharacterized LOC101927963 \\
\hline$L L G L 2$ & $\begin{array}{l}\text { LLGL2, scribble cell polarity complex } \\
\text { component }\end{array}$ \\
\hline SYNE1 & $\begin{array}{l}\text { Spectrin repeat containing nuclear } \\
\text { envelope protein } 1\end{array}$ \\
\hline RAP1GAP2 & RAP1 GTPase activating protein 2 \\
\hline FAM53B & $\begin{array}{l}\text { Family with sequence similarity } 53 \\
\text { member B }\end{array}$ \\
\hline TOGARAM2 & $\begin{array}{l}\text { TOG array regulator of axonemal } \\
\text { microtubules } 2\end{array}$ \\
\hline FRMPD3 & FERM and PDZ domain containing 3 \\
\hline$T B \times 21$ & T-box 21 \\
\hline SESN2 & Sestrin 2 \\
\hline PAX5 & Paired box 5 \\
\hline MIDN & Midnolin \\
\hline
\end{tabular}

Table 3 Genes expressed significantly higher in CD8+ T cells of patients with dermatomyositis than in those with polymyositis (Continued)

\begin{tabular}{|c|c|}
\hline Gene symbol & Gene name \\
\hline CCL5 & C-C motif chemokine ligand 5 \\
\hline SYTL3 & Synaptotagmin like 3 \\
\hline GAB3 & GRB2 associated binding protein 3 \\
\hline TTC38 & Tetratricopeptide repeat domain 38 \\
\hline$L D L R$ & Low density lipoprotein receptor \\
\hline CCL4 & C-C motif chemokine ligand 4 \\
\hline DMWD & DM1 locus, WD repeat containing \\
\hline CASZ1 & Castor zinc finger 1 \\
\hline LAG3 & Lymphocyte activating 3 \\
\hline DYRK1B & $\begin{array}{l}\text { Dual specificity tyrosine phosphorylation } \\
\text { regulated kinase } 1 \mathrm{~B}\end{array}$ \\
\hline GPR153 & G protein-coupled receptor 153 \\
\hline MATK & Megakaryocyte-associated tyrosine kinase \\
\hline SH2D2A & $\mathrm{SH} 2$ domain containing $2 \mathrm{~A}$ \\
\hline RHBDF2 & Rhomboid 5 homolog 2 \\
\hline ADGRG5 & Adhesion G protein-coupled receptor G5 \\
\hline UBE2Q2P1 & $\begin{array}{l}\text { Ubiquitin conjugating enzyme E2 Q2 } \\
\text { pseudogene } 1\end{array}$ \\
\hline GALNT3 & Polypeptide $\mathrm{N}$-acetylgalactosaminyltransferase 3 \\
\hline RUNX3 & Runt related transcription factor 3 \\
\hline PLA2G16 & Phospholipase A2 group XVI \\
\hline SLC15A4 & Solute carrier family 15 member 4 \\
\hline$P P P 2 R 2 B$ & Protein phosphatase 2 regulatory subunit beta \\
\hline RGS9 & Regulator of $\mathrm{G}$ protein signaling 9 \\
\hline PATL2 & PAT1 homolog 2 \\
\hline Clorf21 & Chromosome 1 open reading frame 21 \\
\hline SIPR5 & Sphingosine-1-phosphate receptor 5 \\
\hline TMCC3 & Transmembrane and coiled-coil domain family 3 \\
\hline$T L R 3$ & Toll like receptor 3 \\
\hline GLB1L2 & Galactosidase beta 1 like 2 \\
\hline PRELID2 & PRELI domain containing 2 \\
\hline ADAP1 & ArfGAP with dual PH domains 1 \\
\hline$T R G / 2$ & T cell receptor gamma joining 2 \\
\hline DENND3 & DENN domain containing 3 \\
\hline $50 \times 13$ & SRY-box 13 \\
\hline$G Z M B$ & Granzyme B \\
\hline FGFBP2 & Fibroblast growth factor binding protein 2 \\
\hline RAP2A & RAP2A, member of RAS oncogene family \\
\hline FCRL6 & Fc receptor like 6 \\
\hline ITGAL & Integrin subunit alpha L \\
\hline$A B H D 17 A$ & Abhydrolase domain containing $17 \mathrm{~A}$ \\
\hline CHST12 & Carbohydrate sulfotransferase 12 \\
\hline NBEAL2 & Neurobeachin like 2 \\
\hline
\end{tabular}


Table 3 Genes expressed significantly higher in CD8+ T cells of patients with dermatomyositis than in those with polymyositis (Continued)

\begin{tabular}{|c|c|}
\hline Gene symbol & Gene name \\
\hline ADAM8 & ADAM metallopeptidase domain 8 \\
\hline SLCIA7 & Solute carrier family 1 member 7 \\
\hline LTBP4 & $\begin{array}{l}\text { Latent transforming growth factor beta } \\
\text { binding protein } 4\end{array}$ \\
\hline CRIP1 & Cysteine rich protein 1 \\
\hline RNF166 & Ring finger protein 166 \\
\hline MXD4 & MAX dimerization protein 4 \\
\hline TNFSF9 & TNF superfamily member 9 \\
\hline ZNF683 & Zinc finger protein 683 \\
\hline \multicolumn{2}{|l|}{$\begin{array}{l}\text { CTD- } \\
2377 D 24.8\end{array}$} \\
\hline HNRNPLL & Heterogeneous nuclear ribonucleoprotein L like \\
\hline MPST & mercaptopyruvate sulfurtransferase \\
\hline ATP1A3 & ATPase $\mathrm{Na}^{+} / \mathrm{K}^{+}$transporting subunit alpha 3 \\
\hline IFNLR1 & Interferon lambda receptor 1 \\
\hline PTMS & Parathymosin \\
\hline SLC20A1 & Solute carrier family 20 member 1 \\
\hline MVD & Mevalonate diphosphate decarboxylase \\
\hline SH3RF2 & $\mathrm{SH} 3$ domain containing ring finger 2 \\
\hline RAPGEF1 & Rap guanine nucleotide exchange factor 1 \\
\hline TGFB1 & Transforming growth factor beta 1 \\
\hline \multicolumn{2}{|l|}{ AL928654.3 } \\
\hline BHLHE4O & Basic helix-loop-helix family member e40 \\
\hline MAPKAPK2 & $\begin{array}{l}\text { Mitogen-activated protein kinase-activated protein kin- } \\
\text { ase } 2\end{array}$ \\
\hline PTPRJ & Protein tyrosine phosphatase, receptor type J \\
\hline$D G K Q$ & Diacylglycerol kinase theta \\
\hline MYO3B & Myosin IIIB \\
\hline DUSP8 & Dual specificity phosphatase 8 \\
\hline FLNA & Filamin A \\
\hline NOP14-AS1 & NOP14 antisense RNA 1 \\
\hline ITGB2 & Integrin subunit beta 2 \\
\hline GNG2 & G protein subunit gamma 2 \\
\hline MSC & Musculin \\
\hline ARHGAP10 & Rho GTPase activating protein 10 \\
\hline$D N M B P$ & Dynamin binding protein \\
\hline MYO1G & Myosin IG \\
\hline DDN-AS1 & DDN and PRKAG1 antisense RNA 1 \\
\hline SIPA1 & Signal-induced proliferation-associated 1 \\
\hline AC093616.1 & Anaphase-promoting complex subunit 1-like \\
\hline CTSW & Cathepsin W \\
\hline PXN & Paxillin \\
\hline SSBP3 & Single-stranded DNA binding protein 3 \\
\hline$S L C 2 A 1$ & Solute carrier family 2 member 1 \\
\hline
\end{tabular}

Table 3 Genes expressed significantly higher in CD8+ T cells of patients with dermatomyositis than in those with polymyositis (Continued)

\begin{tabular}{ll}
\hline Gene symbol & Gene name \\
\hline MCOLN2 & Mucolipin 2 \\
NAA50 & $\begin{array}{l}\text { N(alpha)-acetyltransferase 50, NatE } \\
\text { catalytic subunit }\end{array}$ \\
RDH10 & Retinol dehydrogenase 10 \\
NFATC2 & Nuclear factor of activated T cells 2 \\
KDM4B & Lysine demethylase 4B \\
GALNT10 & Polypeptide N-acetylgalactosaminyltransferase 10 \\
DPY19L1P1 & DPY19L1 pseudogene 1 \\
INSIG1 & Insulin induced gene 1 \\
PLEKHA2 & Pleckstrin homology domain containing A2 \\
PROK2 & Prokineticin 2 \\
PTP4A2 & Protein tyrosine phosphatase type IVA, member 2 \\
GPR27 & G protein-coupled receptor 27 \\
LINC00355 & Long intergenic non-protein coding RNA 355
\end{tabular}

The table demonstrates the genes that overlap between the two analytical stages and have a significantly higher expression in CD8+ T cells of patients with dermatomyositis than in those with polymyositis. A false discovery rate threshold of $5 \%$ based on the method of Benjamini-Hochberg was used to identify significant differentially expressed genes

detected in CD8+ T cells and natural killer (NK) cells, but not in CD4+ T cells [37]. This, together with low levels of $S 100 B$ observed in CD4+ T cells in our study, may suggest either that $S 100 B$ expression is evidence of contamination by other cell types or that this expression is characteristic of CD4+ T cells in PM. In any scenario, these data will need replication in an independent group of patients.

The HLA-DRB1*03 haplotype is strongly associated with IIM, especially with PM $[2,38]$. We made an effort to investigate how IIM patients with and without this genetic risk factor are different in their transcriptomic profiles in CD4+ T cells. Six genes were differentially expressed in CD4+ T cells of HLA-DRB1*03-positive compared with HLA-DRB1*03-negative myositis patients. We found that PI4KAP1 had a higher expression in CD4+ $\mathrm{T}$ cells of HLA-DRB1*03-positive myositis and that TRGC2, CTSW, HPCAL4, ZNF683, and GOLGA8B had a higher expression in CD4+ T cells of HLA-DRB1*03-negative myositis patients. Interestingly, we found that ZNF683 also had a higher expression in CD8+ T cells of HLA-DRB1"03-negative myositis patients when comparing PM and DM, suggesting that the expression of ZNF683 is common for both subpopulations of T cells. ZNF683 is upregulated in T cells with cytotoxic characteristics [39] and is involved in the transcriptional regulation of effector functions, such as production of interferon- $\gamma$ and granzyme B [40, 41]. CTSW encodes a protein of the cathepsin family, 
Table 4 Significant Gene Ontology (GO) biological processes in CD8+ T cells of polymyositis and dermatomyositis patients

\begin{tabular}{|c|c|c|c|}
\hline GO biological process complete & Fold enrichment & $p$ value & FDR \\
\hline Lymphocyte migration (GO:0072676) & 11.50 & 1.05E-04 & $4.19 \mathrm{E}-02$ \\
\hline Regulation of T-cell differentiation (GO:0045580) & 10.10 & 4.82E-07 & $2.50 \mathrm{E}-03$ \\
\hline Regulation of lymphocyte differentiation (GO:0045619) & 8.31 & $2.24 \mathrm{E}-06$ & $3.88 \mathrm{E}-03$ \\
\hline Myeloid leukocyte migration (GO:0097529) & 8.17 & $1.26 \mathrm{E}-04$ & 4.69E-02 \\
\hline Response to transforming growth factor beta (GO:0071559) & 6.73 & $1.11 \mathrm{E}-04$ & 4.31E-02 \\
\hline Regulation of leukocyte differentiation (GO:1902105) & 5.48 & 2.05E-05 & $1.68 \mathrm{E}-02$ \\
\hline Regulation of T cell activation (GO:0050863) & 5.26 & 4.48E-06 & $6.34 \mathrm{E}-03$ \\
\hline Leukocyte migration (GO:0050900) & 5.04 & 2.79E-06 & 4.35E-03 \\
\hline Positive regulation of GTPase activity (GO:0043547) & 4.42 & 1.10E-05 & 1.15E-02 \\
\hline Positive regulation of cell adhesion (GO:0045785) & 4.26 & $3.41 \mathrm{E}-05$ & 2.41E-02 \\
\hline Positive regulation of MAPK cascade (GO:0043410) & 3.85 & $1.11 \mathrm{E}-05$ & $1.08 \mathrm{E}-02$ \\
\hline Regulation of GTPase activity (GO:0043087) & 3.75 & $5.71 \mathrm{E}-05$ & 3.18E-02 \\
\hline Regulation of cell activation (GO:0050865) & 3.54 & $2.88 \mathrm{E}-05$ & 2.24E-02 \\
\hline Regulation of leukocyte activation (GO:0002694) & 3.51 & 5.87E-05 & 3.05E-02 \\
\hline Transmembrane receptor protein tyrosine kinase signaling pathway (GO:0007169) & 3.47 & $1.21 \mathrm{E}-04$ & 4.61E-02 \\
\hline Regulation of MAPK cascade (GO:0043408) & 3.42 & $6.96 \mathrm{E}-06$ & 8.34E-03 \\
\hline Regulation of cell adhesion (GO:0030155) & 3.27 & $6.93 \mathrm{E}-05$ & $3.27 E-02$ \\
\hline Enzyme linked receptor protein signaling pathway (GO:0007167) & 3.08 & 7.94E-05 & 3.53E-02 \\
\hline Cell migration (GO:0016477) & 2.91 & $3.48 \mathrm{E}-05$ & 2.35E-02 \\
\hline Positive regulation of immune system process (GO:0002684) & 2.88 & $9.42 \mathrm{E}-06$ & 1.05E-02 \\
\hline Regulation of immune system process (GO:0002682) & 2.75 & 2.77E-07 & 2.16E-03 \\
\hline Positive regulation of intracellular signal transduction (GO:1902533) & 2.75 & 4.75E-05 & 2.84E-02 \\
\hline Regulation of immune response (GO:0050776) & 2.70 & 3.87E-05 & $2.51 \mathrm{E}-02$ \\
\hline Positive regulation of catalytic activity (GO:0043085) & 2.45 & $3.19 E-05$ & 2.36E-02 \\
\hline Immune response (GO:0006955) & 2.41 & $5.32 \mathrm{E}-06$ & $6.91 \mathrm{E}-03$ \\
\hline Cell surface receptor signaling pathway (GO:0007166) & 2.31 & $5.02 \mathrm{E}-07$ & 1.95E-03 \\
\hline Positive regulation of signal transduction (GO:0009967) & 2.31 & $6.66 \mathrm{E}-05$ & 3.24E-02 \\
\hline Positive regulation of molecular function (GO:0044093) & 2.24 & 7.60E-05 & 3.48E-02 \\
\hline Regulation of intracellular signal transduction (GO:1902531) & 2.22 & 3.92E-05 & 2.44E-02 \\
\hline Immune system process (GO:0002376) & 2.21 & $8.12 \mathrm{E}-07$ & 2.11E-03 \\
\hline Regulation of multicellular organismal development (GO:2000026) & 2.15 & 8.34E-05 & $3.61 \mathrm{E}-02$ \\
\hline Positive regulation of response to stimulus (GO:0048584) & 2.14 & 1.65E-05 & $1.51 \mathrm{E}-02$ \\
\hline Regulation of catalytic activity (GO:0050790) & 2.12 & 1.83E-05 & 1.59E-02 \\
\hline Regulation of signal transduction (GO:0009966) & 2.01 & $2.08 \mathrm{E}-06$ & 4.05E-03 \\
\hline Regulation of developmental process (GO:0050793) & 2.00 & 5.79E-05 & 3.11E-02 \\
\hline Regulation of signaling (GO:0023051) & 2.00 & $5.40 \mathrm{E}-07$ & $1.68 \mathrm{E}-03$ \\
\hline Regulation of cell communication (GO:0010646) & 1.99 & 8.44E-07 & $1.88 \mathrm{E}-03$ \\
\hline Regulation of response to stimulus (GO:0048583) & 1.91 & $2.14 \mathrm{E}-07$ & 3.33E-03 \\
\hline Regulation of multicellular organismal process (GO:0051239) & 1.91 & $6.12 \mathrm{E}-05$ & $3.08 \mathrm{E}-02$ \\
\hline Regulation of molecular function (GO:0065009) & 1.84 & $8.55 \mathrm{E}-05$ & 3.60E-02 \\
\hline Signaling (GO:0023052) & 1.58 & 5.65E-05 & 3.26E-02 \\
\hline Cell communication (GO:0007154) & 1.55 & 9.36E-05 & $3.84 \mathrm{E}-02$ \\
\hline
\end{tabular}

GO Gene ontology

Significant GO biological processes for the differentially expressed genes in CD8+ T cells of patients with dermatomyositis and patients with polymyositis. Fisher's exact test with false discovery rate correction $(<0.05)$ was used to determine significant biological processes. The genes mapped to each GO can be found in Additional file 5: Table S10 

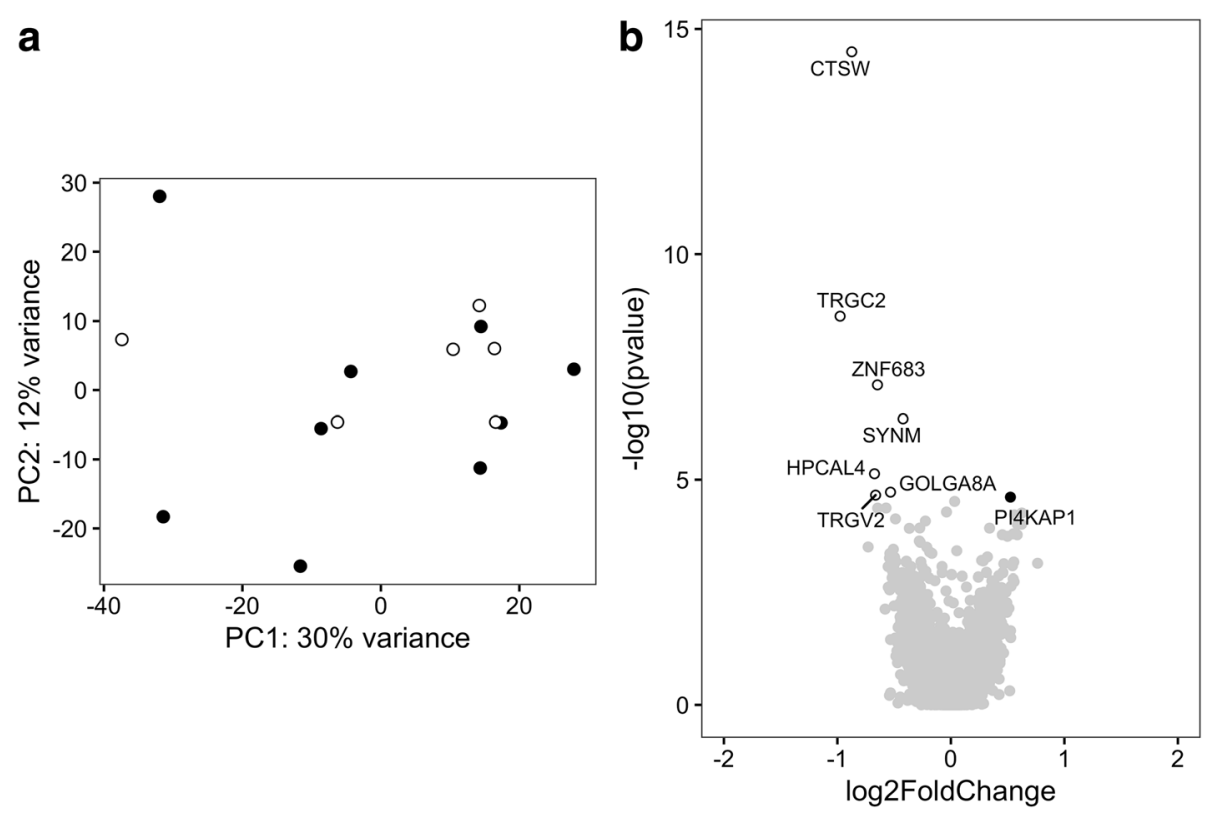

Fig. 5 Gene expression profile in CD4+ T cells of HLA-DRB1*03-positive and -negative patients with myositis. a Principal components (PCs) 1 and 2 plotted according to the HLA-DRB $1 * 03$ status of the patients in a dataset of 21,008 genes $(n=15)$. Samples from HLA-DRB $1 * 03$-positive patients with myositis are represented by filled circles, and those from $H L A-D R B 1 * 03$-negative patients with myositis are represented by open circles. $\mathbf{b}$ Differential genome-wide transcriptomic profile in CD4+ T cells for the contrast between HLA-DRB1*03-positive and -negative patients with myositis. The fold changes $\left(\log _{2}\right)$ are shown on the $x$-axis, and the $p$ values $\left(-\log _{10}\right)$ are shown on the $y$-axis. The genes that are expressed significantly higher in HLA-DRB1*03-positive myositis are shown by filled circles, and the genes expressed significantly higher in $H L A-D R B 1^{*} 03-$ negative myositis are shown by open circles. A false discovery rate threshold of $5 \%$ based on the method of Benjamini-Hochberg was used to identify significant differentially expressed genes

cathepsin W. Cathepsins are found in antigen-presenting cells and are involved in antigen processing [42]. Cathepsin W has been found to be exclusively expressed in CD8 + T cells and NK cells [43]. However, this does not exclude the possibility of differential expression of the transcript in other cell types.

Evidence of differentially expressed genes in whole blood and muscle tissue between various subphenotypes of myositis has been reported previously [22, 44]. These prior investigators found that several type 1 interferon-induced transcripts and proteins were expressed relatively higher in DM patients than in healthy individuals and PM patients. In our study, we did not find type 1 interferon-inducible transcripts to be differentially expressed between PM and DM patients. However, we measured gene expression levels in CD4+ and CD8+ T cells and not in interferon-producing plasmacytoid dendritic cells. In addition, most of the patients in our study were receiving prednisone and additional immunosuppressive drugs that may significantly suppress the type 1 interferon-inducible signature [45].

The limited number of patients with PM and DM, which is the major weakness of our study, did not allow us to consider contribution of autoantibody positivity in the statistical model. The majority of patients in our study had autoantibodies of different specificities (Table 1). It has been shown that anti-MDA5 antibodies are associated with DM complicated by rapidly progressive interstitial lung disease (ILD) [46]. In addition, anti-TIF1- $\gamma$ antibodies have been associated with cancerassociated DM [47]. Furthermore, anti-Jo-1 antibodies are strongly associated with a clinical phenotype named anti-synthetase syndrome, characterized by ILD, arthritis, mechanic's hands, and myositis [48]. Further studies with a high number of myositis patients are needed to address correlations between transcriptomic profile and autoantibodies. Moreover, the differences in gene expression levels need to be confirmed at the protein level and in further functional studies.

\section{Conclusions}

In the current study, we analyzed, for the first time to our knowledge, the transcriptomic profiles of different subpopulations of $\mathrm{T}$ cells in patients with PM or DM and could demonstrate that these two clinical phenotypes differ regarding $\mathrm{T}$-cell phenotypes related to gene 

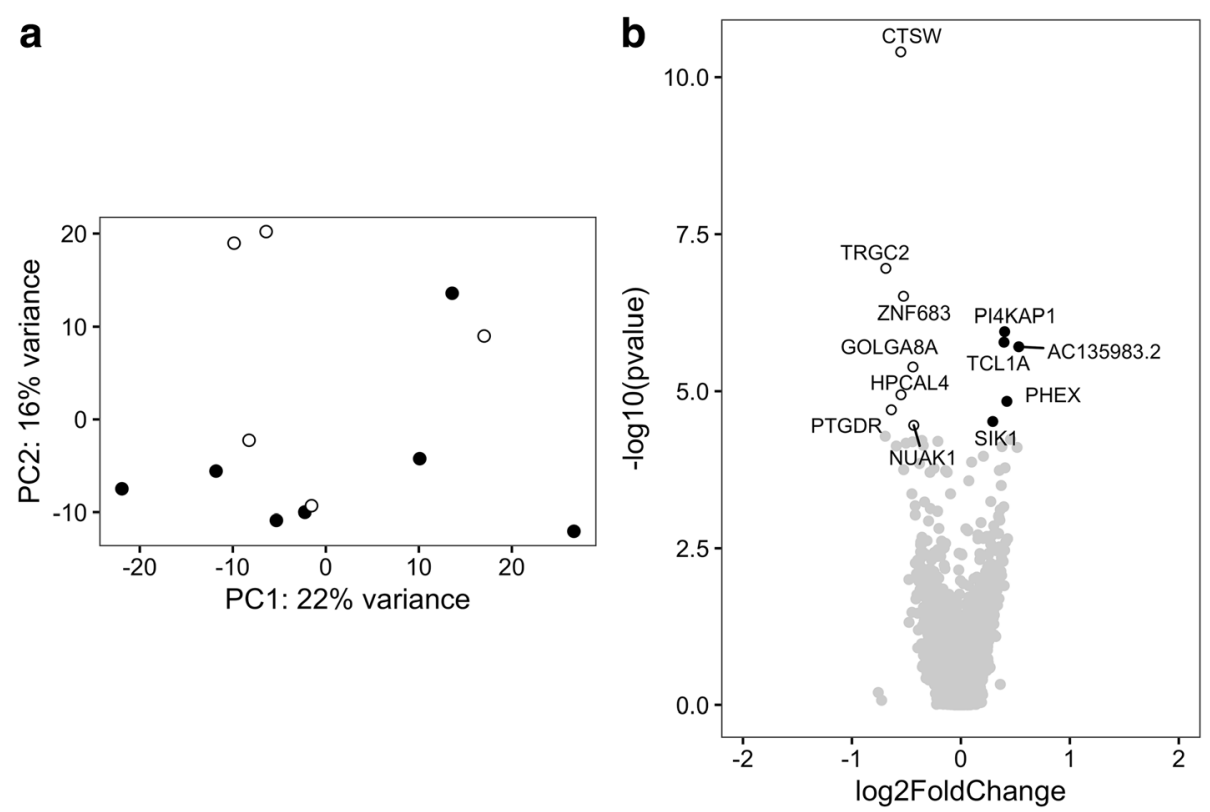

Fig. 6 Gene expression profile in CD4+ T cells of HLA-DRB1*03-positive and -negative patients with myositis excluding potential outliers. a Principal components (PCs) 1 and 2 plotted according to the HLA-DRB1*03 status of the patients in a dataset of 20,091 genes $(n=12)$. Samples from HLA-DRB1*03positive patients with myositis are represented by filled circles, and those from $H L A-D R B 1 * 03$-negative patients with myositis are represented by open circles. b Differential genome-wide transcriptomic profile in CD4+ T cells for the contrast between HLA-DRB1*03-positive and -negative patients with myositis. The fold changes $\left(\log _{2}\right)$ are shown on the $x$-axis, and the $p$ values $\left(-\log _{10}\right)$ are shown on the $y$-axis. The genes that are expressed significantly higher in $H L A$ $D R B 1 * 03$-positive patients with myositis are shown by filled circles, and the genes expressed significantly higher in $H L A-D R B 1 * 03$-negative patients with myositis are shown by dark open circles. A false discovery rate threshold of $5 \%$ based on the method of Benjamini-Hochberg was used to identify significant differentially expressed genes

expression. It is evident that these differences are more profound for CD8+ T cells when comparing PM patients with DM patients. Although the differentially expressed genes will need to be confirmed in a larger group of patients, these alterations in the transcriptomes of PM and DM patients suggest different immune mechanisms involved in different subphenotypes of IIM.

\section{Additional files}

Additional file 1: Additional clinical characteristics of patients included in this study. Tables S1-S3 provide additional clinical characteristics of patients included in this study regarding PM and DM. Table S1 includes all patients, whereas, Tables S2 and S3 contain the data for the CD4+ and CD8+ T-cell subsets, respectively. Tables S4 and S5 provide additional clinical characteristics of patients included in this study regarding HLA$D R B 1^{*} 03$ status. Table $\$ 4$ includes all patients, whereas Table $\$ 5$ contains the data for the CD4+ T-cell subset. (DOCX $24 \mathrm{~kb}$ )

Additional file 2: Differentially expressed genes for CD4+ T cells of PM and DM patients. Table S6 and S7 provide differentially expressed genes for CD4+ T cells of PM and DM patients at analytical stage 1 (including potential outliers) and analytical stage 2 (excluding potential outliers), respectively. (DOCX $18 \mathrm{~kb}$ )

Additional file 3: Clustering heat map showing cellular heterogeneity in CD4+ and CD8+ T-cell subsets. Figure S1 shows a clustering heat map indicating cellular heterogeneity in CD4+ and CD8+ T-cell subsets, which indicates minor contamination of other cell types in these subsets. (DOCX $290 \mathrm{~kb})$
Additional file 4: Differentially expressed genes for CD8+ T cells of PM and DM patients. Tables 58 and 59 provide differentially expressed genes for CD8+ T cells of PM and DM patients at analytical stage 1 (including potential outliers) and analytical stage 2 (excluding potential outliers), respectively. (DOCX $106 \mathrm{~kb}$ )

Additional file 5: Gene Ontology biological processes for the differentially expressed genes in CD8+ T cells of PM and DM patients. Table S10 shows the genes mapped to the enriched GO biological processes for the differentially expressed genes in CD8+ T cells of PM and DM patients. (DOCX $17 \mathrm{~kb}$ )

Additional file 6: Differentially expressed genes in CD4+ T cells of HLA$D R B 1^{*} 03$-positive and -negative myositis patients. Table S11 and S12 provide differentially expressed genes for CD4+ T cells of HLA-DRB1*03positive and -negative myositis patients at analytical stage 1 (including potential outliers) and analytical stage 2 (excluding potential outliers), respectively. (DOCX $16 \mathrm{~kb}$ )

\section{Abbreviations}

DM: Dermatomyositis; FDR: False discovery rate; GO: Gene Ontology; IIM: Idiopathic inflammatory myopathy; ILD: Interstitial lung disease; NK: Natural killer; PBMC: Peripheral blood mononuclear cell; PC: Principal component; PCA: Principal component analysis; PM: Polymyositis; RIN: RNA integrity number; SNP: Single-nucleotide polymorphism; TCR: T-cell receptor; TGF: Transforming growth factor

\section{Acknowledgements}

We are very thankful to Dr. Yvonne Sundström, Dr. Danika Schepis, and Dr. Louise Berg for running flow cytometry on sorted cell populations. We thank Dr. Z. E. Betteridge (RNA and protein immunoprecipitation) and Prof. J. Rönnelid (line immunoassay) for their collaboration in autoantibody detection. Transcriptomic profiling was performed by the SNP\&SEQ Technology Platform in Uppsala. This facility is part of the National Genomics 
Infrastructure (NGI) Sweden and Science for Life Laboratory. The SNP\&SEQ Technology Platform is also supported by the Swedish Research Council and the Knut and Alice Wallenberg Foundation. The computations were performed on resources provided by SNIC through Uppsala Multidisciplinary Center for Advanced Computational Science (UPPMAX), supported by NGI Sweden

\section{Funding}

This study was supported by a collaborative grant between the Mayo Clinic and Karolinska Institutet, the Swedish Research Council, the Swedish Rheumatism Association, King Gustaf V's 80-year foundation, and the regional agreement on medical training and clinical research (ALF) between Stockholm County Council and Karolinska Institutet.

\section{Availability of data and materials}

Raw data from RNA sequencing are available from the authors (LP) upon request. Clinical data are not available currently, owing to protection regulations for personal information.

\section{Authors' contributions}

$M H, L E, A M R$, IEL, and LP were involved with the conception and design of the present study. LE and IEL provided clinical data. MH and EH performed the experiments. MH analyzed and interpreted the data. LE, KC, VM, IEL, and LP contributed to the interpretation of the results. MH and LP drafted the manuscript. All authors reviewed and edited the manuscript. All authors read and approved the final manuscript.

\section{Ethics approval and consent to participate}

Ethics approval was provided by permission from the Stockholm Regional Ethics Board and by written consent from the patients.

\section{Consent for publication}

Not applicable.

\section{Competing interests}

The authors declare that they have no competing interests.

\section{Publisher's Note}

Springer Nature remains neutral with regard to jurisdictional claims in published maps and institutional affiliations.

\section{Author details}

'Division of Rheumatology, Department of Medicine, Karolinska Institutet, Karolinska University Hospital, Stockholm, Sweden. ${ }^{2}$ Department of Pediatrics, Duke Children's Hospital, Duke University Medical Center, Durham, USA.

Received: 26 May 2018 Accepted: 29 July 2018

Published online: 29 August 2018

\section{References}

1. Dalakas MC, Hohlfeld R. Polymyositis and dermatomyositis. Lancet. 2003;362: 971-82.

2. Rothwell S, Cooper RG, Lundberg IE, Miller FW, Gregersen PK, Bowes J, et al. Dense genotyping of immune-related loci in idiopathic inflammatory myopathies confirms HLA alleles as the strongest genetic risk factor and suggests different genetic background for major clinical subgroups. Ann Rheum Dis. 2016;75:1558-66.

3. Hirsch TJ, Enlow RW, Bias WB, Arnett FC. HLA-D related (DR) antigens in various kinds of myositis. Hum Immunol. 1981;3:181-6.

4. O'Hanlon TP, Carrick DM, Arnett FC, Reveille JD, Carrington M, Gao X, et al. Immunogenetic risk and protective factors for the idiopathic inflammatory myopathies: distinct HLA-A, -B, -CW, -DRB1 and -DQA1 allelic profiles and motifs define clinicopathologic groups in Caucasians. Medicine. 2005;84: $338-49$

5. Ghirardello A, Bassi N, Palma L, Borella E, Domeneghetti M, Punzi L, et al. Autoantibodies in polymyositis and dermatomyositis. Curr Rheumatol Rep. 2013;15:335

6. Arahata K, Engel AG. Monoclonal antibody analysis of mononuclear cells in myopathies. I: quantitation of subsets according to diagnosis and sites of accumulation and demonstration and counts of muscle fibers invaded by $T$ cells. Ann Neurol. 1984;16:193-208.
7. Engel AG, Arahata K. Monoclonal antibody analysis of mononuclear cells in myopathies. II: phenotypes of autoinvasive cells in polymyositis and inclusion body myositis. Ann Neurol. 1984;16:209-15.

8. Goebels N, Michaelis D, Engelhardt M, Huber S, Bender A, Pongratz D, et al. Differential expression of perforin in muscle-infiltrating $T$ cells in polymyositis and dermatomyositis. J Clin Invest. 1996;97:2905-10.

9. Orimo S, Koga R, Goto K, Nakamura K, Arai M, Tamaki M, et al. Immunohistochemical analysis of perforin and granzyme a in inflammatory myopathies. Neuromuscul Disord. 1994;4:219-26.

10. Fasth AER, Dastmalchi M, Rahbar A, Salomonsson S, Pandya JM, Lindroos E, et al. T cell infiltrates in the muscles of patients with dermatomyositis and polymyositis are dominated by CD28 ${ }^{\text {null }} T$ cells. J Immunol. 2009;183:4792-9.

11. Pandya JM, Venalis P, Al-Khalili L, Hossain MS, Stache V, Lundberg IE, et al. $\mathrm{CD}^{+}$and $\mathrm{CD} 8^{+} \mathrm{CD} 28^{\text {null }} T$ cells are cytotoxic to autologous muscle cells in patients with polymyositis. Arthritis Rheumatol. 2016;68:2016-26.

12. Benveniste $\mathrm{O}$, Chérin $\mathrm{P}$, Maisonobe $\mathrm{T}$, Merat $\mathrm{R}$, Chosidow $\mathrm{O}$, Mouthon $\mathrm{L}$, et al. Severe perturbations of the blood T cell repertoire in polymyositis, but not dermatomyositis patients. J Immunol. 2001;167:3521-9.

13. Lundberg IE, Tjärnlund $\mathrm{A}$, Bottai $\mathrm{M}$, Werth VP, Pilkington $\mathrm{C}$, de Visser $\mathrm{M}$, et al. 2017 European League Against Rheumatism/American College of Rheumatology classification criteria for adult and juvenile idiopathic inflammatory myopathies and their major subgroups. Ann Rheum Dis. 2017; 76:1955-64.

14. Bohan A, Peter JB. Polymyositis and dermatomyositis (first of two parts). N Engl J Med. 1975;292:344-7.

15. Bohan A, Peter JB. Polymyositis and dermatomyositis (second of two parts). N Engl J Med. 1975;292:403-7.

16. Olerup O, Zetterquist H. HLA-DR typing by PCR amplification with sequence-specific primers (PCR-SSP) in 2 hours: an alternative to serological DR typing in clinical practice including donor-recipient matching in cadaveric transplantation. Tissue Antigens. 1992;39:225-35.

17. Dobin A, Davis CA, Schlesinger F, Drenkow J, Zaleski C, Jha S, et al. STAR: ultrafast universal RNA-seq aligner. Bioinformatics. 2013;29:15-21.

18. Aran $\mathrm{D}, \mathrm{Hu} Z$ Z, Butte AJ. xCell: digitally portraying the tissue cellular heterogeneity landscape. Genome Biol. 2017;18:220.

19. Patro R, Duggal G, Love MI, Irizarry RA, Kingsford C. Salmon: fast and biasaware quantification of transcript expression using dual-phase inference. Nat Methods. 2017:14:417-9.

20. Love MI, Huber W, Anders S. Moderated estimation of fold change and dispersion for RNA-seq data with DESeq2. Genome Biol. 2014:15:550.

21. Szodoray P, Alex P, Knowlton N, Centola M, Dozmorov I, Csipo I, et al. Idiopathic inflammatory myopathies, signified by distinctive peripheral cytokines, chemokines and the TNF family members B-cell activating factor and a proliferation inducing ligand. Rheumatology (Oxford). 2010;49:1867-77.

22. Greenberg SA, Sanoudou D, Haslett JN, Kohane IS, Kunkel LM, Beggs AH, et al. Molecular profiles of inflammatory myopathies. Neurology. 2002;59:117082.

23. Albrecht I, Wick C, Hallgren Å, Tjärnlund A, Nagaraju K, Andrade F, et al. Development of autoantibodies against muscle-specific FHL1 in severe inflammatory myopathies. J Clin Invest. 2015;125:4612-24.

24. Levine Stuart M, Raben N, Xie D, Askin Frederic B, Tuder R, Mullins M, et al. Novel conformation of histidyl-transfer RNA synthetase in the lung. Arthritis Rheum. 2007;56:2729-39.

25. Englund P, Wahlström J, Fathi M, Rasmussen E, Grunewald J, Tornling G, et al. Restricted T cell receptor BV gene usage in the lungs and muscles of patients with idiopathic inflammatory myopathies. Arthritis Rheum. 2007;56: 372-83.

26. Confalonieri P, Bernasconi P, Cornelio F, Mantegazza R. Transforming growth factor- $\beta 1$ in polymyositis and dermatomyositis correlates with fibrosis but not with mononuclear cell infiltrate. J Neuropathol Exp Neurol. 1997;56:479-84.

27. Dominguez CX, Amezquita RA, Guan T, Marshall HD, Joshi NS, Kleinstein SH, et al. The transcription factors ZEB2 and T-bet cooperate to program cytotoxic T cell terminal differentiation in response to LCMV viral infection. J Exp Med. 2015;212:2041-56.

28. Omilusik KD, Best JA, Yu B, Goossens S, Weidemann A, Nguyen JV, et al. Transcriptional repressor ZEB2 promotes terminal differentiation of CD8+ effector and memory T cell populations during infection. J Exp Med. 2015 212:2027-39.

29. Verschueren K, Remacle JE, Collart C, Kraft H, Baker BS, Tylzanowski P, et al. SIP1, a novel zinc finger/homeodomain repressor, interacts with Smad 
proteins and binds to $5^{\prime}$-CACCT sequences in candidate target genes. J Biol Chem. 1999;274:20489-98.

30. Li J, Mahajan A, Tsai MD. Ankyrin repeat: a unique motif mediating proteinprotein interactions. Biochemistry. 2006;45:15168-78.

31. Stahl EA, Raychaudhuri S, Remmers EF, Xie G, Eyre S, Thomson BP, et al. Genome-wide association study meta-analysis identifies seven new rheumatoid arthritis risk loci. Nat Genet. 2010;42:508-14.

32. Okada Y, Wu D, Trynka G, Raj T, Terao C, Ikari K, et al. Genetics of rheumatoid arthritis contributes to biology and drug discovery. Nature. 2014;506:376-81.

33. Eyre S, Bowes J, Diogo D, Lee A, Barton A, Martin P, et al. High density genetic mapping identifies new susceptibility loci for rheumatoid arthritis. Nat Genet. 2012;44:1336-40.

34. Jostins L, Ripke S, Weersma RK, Duerr RH, McGovern DP, Hui KY, et al. Hostmicrobe interactions have shaped the genetic architecture of inflammatory bowel disease. Nature. 2012;491:119-24.

35. Alloza I, Otaegui D, de Lapuente AL, Antigüedad A, Varadé J, Núñez C, et al. ANKRD55 and DHCR7 are novel multiple sclerosis risk loci. Genes Immun. 2011;13:253-7.

36. Zimmer DB, Cornwall EH, Landar A, Song W. The S100 protein family: history, function, and expression. Brain Res Bull. 1995;37:417-29.

37. Steiner J, Marquardt N, Pauls I, Schiltz K, Rahmoune H, Bahn S, et al. Human CD8+ T cells and NK cells express and secrete S100B upon stimulation. Brain Behav Immun. 2011;25:1233-41.

38. Miller FW, Chen W, O'Hanlon TP, Cooper RG, Vencovsky J, Rider LG, et al. Genome-wide association study identifies HLA 8.1 ancestral haplotype alleles as major genetic risk factors for myositis phenotypes. Genes Immun. 2015;16:470-80.

39. Oja AE, Vieira Braga FA, Remmerswaal EBM, Kragten NAM, Hertoghs KML, Zuo J, et al. The transcription factor Hobit identifies human cytotoxic CD4 ${ }^{+}$ T cells. Front Immunol. 2017;8:325.

40. Mackay LK, Minnich M, Kragten NAM, Liao Y, Nota B, Seillet C, et al. Hobit and Blimp1 instruct a universal transcriptional program of tissue residency in lymphocytes. Science. 2016;352:459-63.

41. van Gisbergen KPJM, Kragten NAM, Hertoghs KML, Wensveen FM, Jonjic S, Hamann J, et al. Mouse Hobit is a homolog of the transcriptional repressor Blimp-1 that regulates NKT cell effector differentiation. Nat Immunol. 2012; 13:864-71.

42. Hsing L C, Rudensky AY. The lysosomal cysteine proteases in MHC class II antigen presentation. Immunol Rev. 2005;207:229-41.

43. Stoeckle C, Gouttefangeas C, Hammer M, Weber E, Melms A, Tolosa E. Cathepsin W expressed exclusively in CD8+ T cells and NK cells, is secreted during target cell killing but is not essential for cytotoxicity in human CTLS. Exp Hematol. 2009;37:266-75.

44. Walsh RJ, Kong SW, Yao Y, Jallal B, Kiener PA, Pinkus JL, et al. Type I interferon-inducible gene expression in blood is present and reflects disease activity in dermatomyositis and polymyositis. Arthritis Rheum. 2007; 56:3784-92.

45. de Jong TD, Vosslamber S, Blits M, Wolbink G, Nurmohamed MT, van der Laken $\mathrm{CJ}$, et al. Effect of prednisone on type I interferon signature in rheumatoid arthritis: consequences for response prediction to rituximab. Arthritis Res Ther. 2015;17:78.

46. Cao H, Pan M, Kang Y, Xia Q, Li X, Zhao X, et al. Clinical manifestations of dermatomyositis and clinically amyopathic dermatomyositis patients with positive expression of anti-melanoma differentiation-associated gene 5 antibody. Arthritis Care Res (Hoboken). 2012;64:1602-10.

47. Trallero-Araguás E, Rodrigo-Pendás Jose Á, Selva-O'Callaghan A, MartínezGómez X, Bosch X, Labrador-Horrillo M, et al. Usefulness of anti-p155 autoantibody for diagnosing cancer-associated dermatomyositis: a systematic review and meta-analysis. Arthritis Rheum. 2012;64:523-32.

48. Fathi M, Dastmalchi M, Rasmussen E, Lundberg I, Tornling G. Interstitial lung disease, a common manifestation of newly diagnosed polymyositis and dermatomyositis. Ann Rheum Dis. 2004;63:297-301.

Ready to submit your research? Choose BMC and benefit from:

- fast, convenient online submission

- thorough peer review by experienced researchers in your field

- rapid publication on acceptance

- support for research data, including large and complex data types

- gold Open Access which fosters wider collaboration and increased citations

- maximum visibility for your research: over $100 \mathrm{M}$ website views per year

At BMC, research is always in progress.

Learn more biomedcentral.com/submissions 